\title{
Spontaneous midgestation abortion associated with Bacteroides fragilis: A case report
}

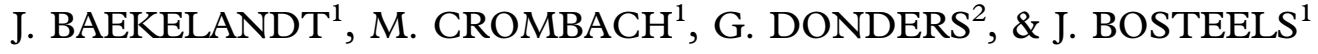 \\ ${ }^{1}$ Department of Obstetrics and Gynecology, AZ Imeldaziekenhuis, Bonheiden, Belgium, and ${ }^{2}$ Department of Obstetrics and \\ Gynecology, Heilig Hartziekenhuis, Tienen, Belgium
}

\section{Introduction}

Intrauterine infection underlies many spontaneous mid-gestation abortions. We present a case of midtrimester abortion, where Bacteroides fragilis was the sole pathogen that could be cultured.

\section{Case report}

A 31-year-old primigravida consulted her gynaecologist in the casualty department of a private hospital in Belgium (Imeldaziekenhuis Bonheiden) with intermittent contractions presenting as lower back pain, vague hypogastric cramps and vaginal discharge of blood and mucus. She was 19 weeks and 3 days pregnant according to dates of conception and an ultrasound at 7 weeks. Her medical history was unremarkable. Serology for CMV IgG, Hepatitis A $\mathrm{IgG}$, Hepatitis B surface antigen and Hepatitis C IgG was negative and there was no immunity for Toxoplasmosis. Routine ultrasound at 18 weeks was unremarkable.

A few days prior to her admission in the hospital she recalled vague flu-like symptoms and diarrhoea. Before these symptoms started she had eaten cheese, made with non-pasteurised milk.

On admission she had no fever, her abdomen and uterus were soft, non-tender and adequately sized for 19 weeks gestation. A sterile speculum examination revealed bulging membranes and a bloody discharge. Fetal membranes were intact.

An ultrasound showed an anatomically normal, very active fetus, with biometry compatible with 19 weeks gestation, normal amount of amniotic fluid, and normal placenta. On abdominal ultrasound the cervix appeared to be $3 \mathrm{~cm}$ dilated and fully effaced.
The C-reactive protein (CRP) was normal (0.92 $\mathrm{mg} / \mathrm{dl}$ ) and the leucocytosis was up to $19300 /$ $\mathrm{mm}$ with $85 \%$ neutrofils. Urinary culture was negative.

Based on the patient's history, chorioamnionitis, possibly due to Listeria monocytogenes from the cheese, was assumed. Because of the infectious risk, the decision was made not to administer tocolysis, nor to perform a cervical cerclage. Amoxycillineclavulanic acid was administered IV $1 \mathrm{~g}$ every 6 hours. Despite this treatment the patient developed $38.4^{\circ} \mathrm{C}$ fever and uterine contractions within 12 hours. The CRP had risen to $2.78 \mathrm{mg} / \mathrm{dl}$ with a leucocytosis of $20500 / \mathrm{mm}$ ( $80 \%$ neutrofil count). Vaginal GBS swab cultured on a GBS selective medium was negative and aerobe and anaerobe blood cultures remained negative as well.

A male fetus with Apgar 0 was promptly delivered.

Anatomopathological examination showed an immature placenta with intervillous microabcesses containing necrotic debris. The membranes showed severe signs of chorioamnionitis. The fetus showed no congenital abnormalities and no signs of pneumonitis.

Cultures taken from the placenta and the fetus both showed infection with $B$. fragilis.

The patient recovered quickly and was discharged from the hospital on day 4 on oral antibiotic treatment, without a fever.

\section{Discussion}

The role of ascending genital infection, leading to amniotic fluid infection and preterm labor is well recognized in midtrimester miscarriages [1-10]. Prior rupture of membranes is not necessary for 
development of ascending amniotic infection [11]. It has been established that subclinical intrauterine infection may occur, even with intact membranes, leading to the absence of clinical signs of infection, despite clear histological signs of chorioamnionitis [12]. Micro-organisms can be recovered from the retro-chorioamniotic space in cases with preterm labor at early gestational age and histological chorioamnionitis can usually be demonstrated [6] Furthermore, the earlier the gestational age, the higher is the rate of histological chorioamnionitis and amniotic fluid infection [11].

There are two likely mechanisms of fetal loss associated with infection in midgestation and both are similar to those operating later in pregnancy. First, there may be bacterial invasion of the amniotic cavity or fetoplacental membranes, stimulating labor and delivery of a previable fetus, and second, there may be intrauterine infection of the fetus presumably from swallowed and inhaled infected amniotic fluid, leading to fetal pneumonitis and/or septicaemia [12].

McDonald (1991) demonstrated preterm labor to be associated with the recovery of bacterial microorganisms in the vagina during labor. Both microorganisms linked to bacterial vaginosis ( $G$. vaginalis, Bacteroides) and aerobic organisms (E. coli, group B streptococci) were involved [5]. Bacteroides $\mathrm{sp}$. were shown to be significantly associated with PROM, whereas no such relationship was present with $G$. vaginalis. [5]. Minkoff et al. (1984) demonstrated that women colonised with Bacteroides had a relative risk of 2.8 for PROM compared with noncarriers [13].

The role of vaginal microorganisms in late miscarriage was also demonstrated in a study of 783 women screened in early pregnancy, showing a 7 fold increased risk of preterm birth and late miscarriage (16-24 weeks of gestation) in women with abnormal vaginal flora compared to normal flora [14]. As most of these midtrimester abortion cases had rather intermediate flora (mixed anaerobic-aerobic flora) than full blown bacterial vaginosis, it led our group to propose a revision of the current opinion of the pathogenesis of infection-related preterm birth [15]. Indeed numerous studies now relate anaerobic $[8,14]$ bacterial vaginosis and not aerobic vaginitis to early pregnancy losses, whereas in the second half of pregnancy, preterm birth is rather associated with aerobic vaginitis than with uncomplicated anaerobic bacterial vaginosis $[12,16,17]$.

Later in pregnancy, at 24-32 weeks, not infrequently the aerobic group, B streptococci, with or without Candida albicans are the sole organisms found, and in a recent study on the preterm birth risk early in pregnancy, it could be confirmed that not the anaerobic bacterial vaginosis at first prenatal visit matters so much for a preterm delivery between 20 and 34 weeks, but rather aerobic vaginitis due to group B strep, E. coli and other aerobes [16].

\section{Summary}

A midtrimester pregnancy loss, due to $B$. fragilis is described. We hypothesize that in early pregnancy anaerobic bacterial vaginosis has the greatest pathogenicity, while an intermediate (mixed) flora is most dangerous in midtrimester miscarriages, and that aerobic vaginitis is more dangerous than anaerobes towards the second half of the pregnancy. Unfortunately, no screen and treat policy has yet been proven to be sufficiently powerful to prevent the vast majority of infection-related prematurity.

\section{References}

1. Gravett MG, Hummel D, Eschenbach DA, Holmes KK. Preterm labor associated with subclinical amniotic fluid infection and with bacterial vaginosis. Obstet Gynecol 1986;67:229-237.

2. Lamont RF, Taylor-Robinson D, Wigglesworth JS, Furr PM, Evans RT, Elder MG. The role of mycoplasmas, ureaplasmas and chlamydiae in the genital tract of women presenting in spontaneous early premature labor. Med Microbiol 1987;24:253-257.

3. Hillier SL, Martius J, Krohn M, Kiviat N, Holmes KK, Eschenbach DA. A case-control study of chorioamnionitic infection and histological chorioamnionitis in prematurity. N Engl J Med 1988;319:972-978.

4. Romero R, Sirtori M, Oyarzun E, Avila C, Mazor M, Callahan R, Sabo V, Athanassiadis AP, Hobbins JC. Infection and labor: Prevalence, microbiology and clinical significance of intraamniotic infection in women with preterm labor and intact membranes. Am J Obstet Gynecol 1989; 161:817-824.

5. McDonald HM, O'Loughlin JA, Jolley P, Vigneswaran R, McDonald PJ: Vaginal infection and preterm labor. $\mathrm{Br} \mathrm{J}$ Obstet Gynaecol 1991;99:427-435.

6. Hillier SL, Krohn MA, Kiviat NB, Watts DH, Eschenbach DA. Microbiologic causes and neonatal outcomes associated with chorioamnion infection. Am J Obstet Gynecol 1991;165:955-961.

7. Donders GGG, Odds A, Vereecken A, Van Bulck B, Caudron J, Londers L, Salembier G, Spitz B. Abnormal vaginal flora in the first trimester, but not full-blown bacterial vaginosis is associated with premature birth. Prenat Neonat Med 1998;3:588-593.

8. Donders GGG, Van Bulck B, Caudron J, Londers L, Vereecken A, Spitz B. Bacterial vaginosis and mycoplasmata increase the risk of spontaneous abortion. Am J Obstet Gynecol 2000;183:431-437.

9. Andersen LF, Svare J, Madsen H, Langhoff-Roos J, Jensen ET, Bruun BB. Group B streptococcal chorioamnionitis and neonatal septicemia following 8 days pivampicillin and metronidazol prophylaxis after premature rupture of membranes; a case report: Eur J Obstet Gynecol Reprod Biol 1991;38:157-160.

10. Krohn MA, Thwinn SS, Rabe LK, Brown Z, Hillier S. Vaginal colonization by $E$. coli as a risk factor for very low birth weight delivery and other perinatal complications. J Infect Dis 1997;175:606-610. 
11. Naeye RL, Peters EC. Causes and consequences of premature rupture of fetal membranes. Lancet 1980;1:192-194.

12. McDonald HM, Chambers HM. Intrauterine infection and spontaneous midgestation abortion: is the spectrum of microorganisms similar to that in preterm labor? Infect Dis Obstet Gynecol 2000;8(5-6):220-227.

13. Minkoff H, Grunebaum AN, Schwarz RH, Feldman J, Cummings $M$, Crombleholme W, Clark L, Pringle G, McCormack WM. Risk factors for prematurity and premature rupture of membranes : a prospective study of the vaginal flora in pregnancy. Am J Obstet Gynecol 1984;150:965-972.

14. Hay PE, Lamont RF, Taylor-Robinson D, Morgan DJ, Ison C, Pearson J. Abnormal bacterial colonization of the genital tract and subsequent preterm delivery and late miscarriage. $\mathrm{Br}$ Med J 1994;308:295-298.
15. Donders GGG. Bacterial vaginosis in pregnancy: screen and treat? (Editorial) Eur J Obstet Gynecol Reprod Biol 1999; 83:1-4.

16. Donders GGG, Vereecken A, Bosmans E, Dekeersmaecker A, Salembier G, Spitz B. Definition of a type of abnormal vaginal flora that is distinct from bacterial vaginosis: aerobic vaginitis. Br J Obstet Gynecol 2002;109:1-10.

17. Carey JC, Klebanoff MA, Hauth JC, Hillier SL, Thom EA, Ernest JM, Heine P, Nugent RP, Fischer ML, Leven KJ, Metronidazole to prevent preterm delivery in pregnant women with asymptomatic bacterial vaginosis. N Engl J Med 2000; 342:534-540. 


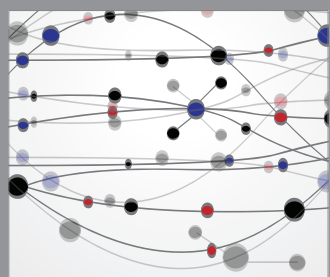

The Scientific World Journal
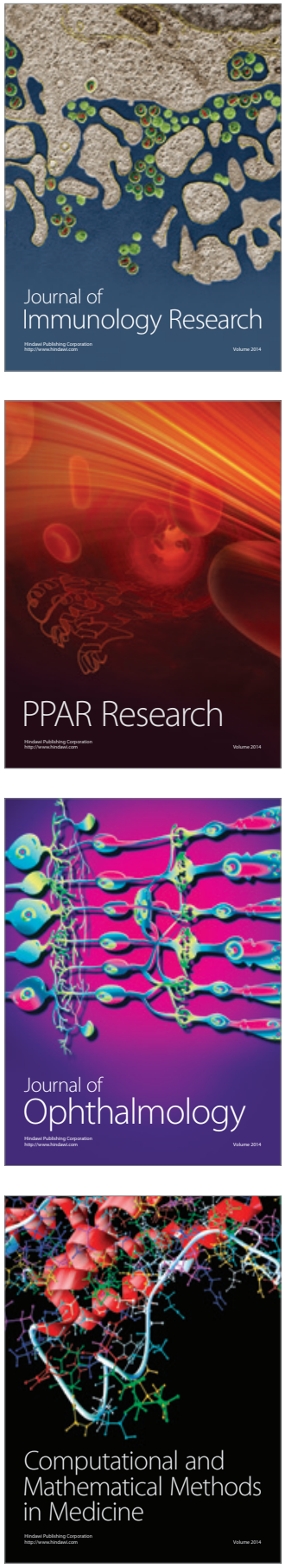

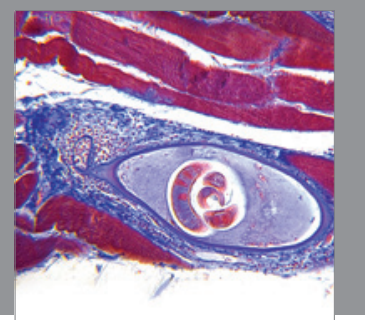

Gastroenterology

Research and Practice
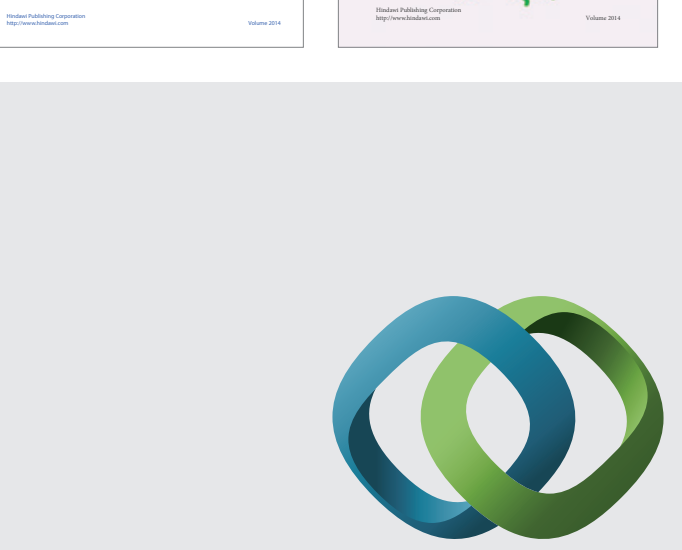

\section{Hindawi}

Submit your manuscripts at

http://www.hindawi.com
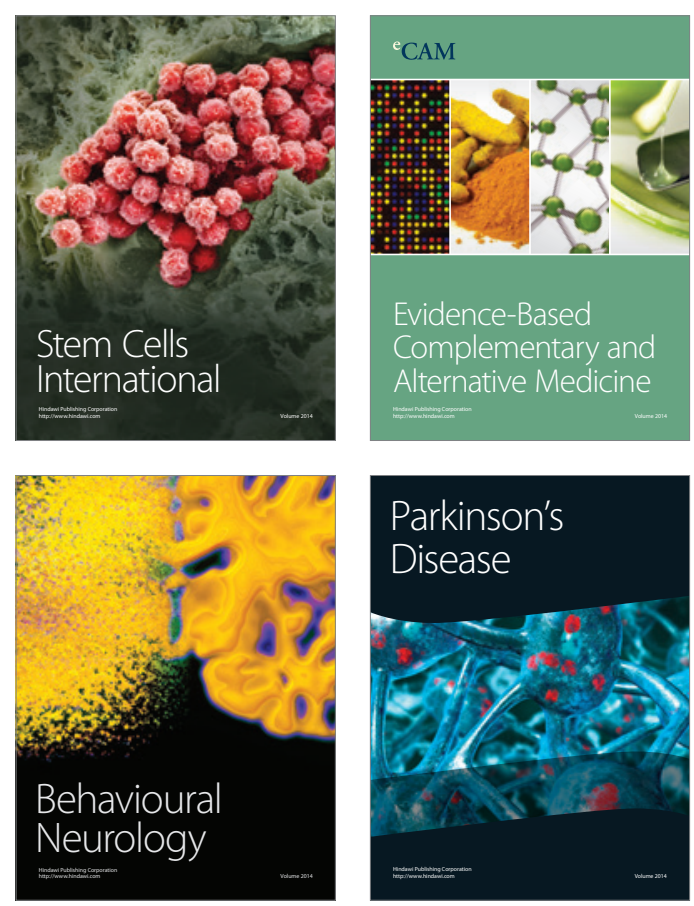

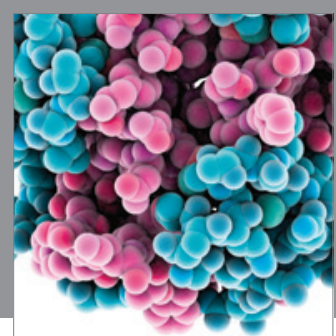

Journal of
Diabetes Research

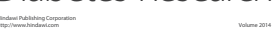

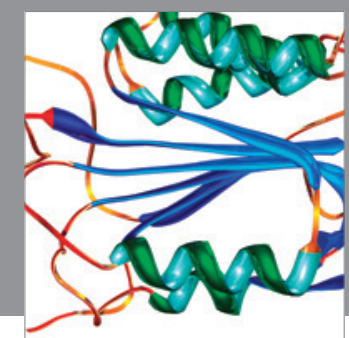

Disease Markers
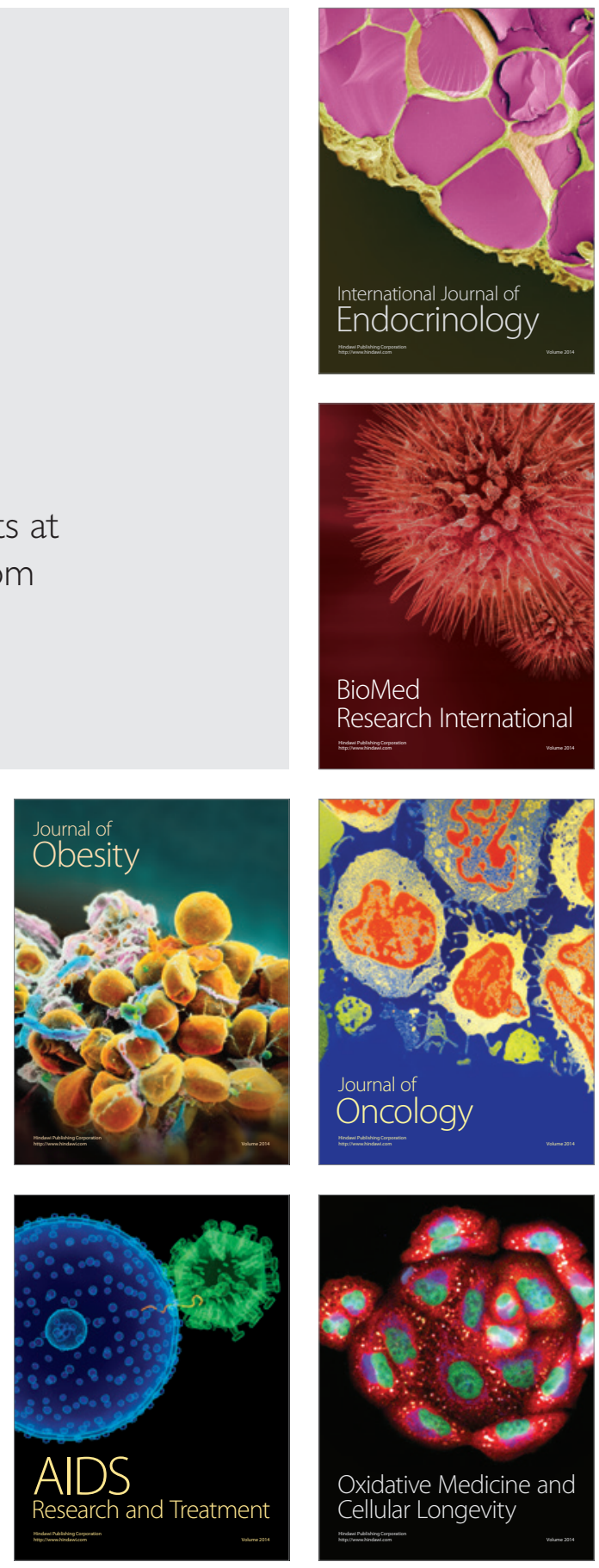